\title{
Eosinophil counts in first COPD hospitalizations: a comparison of health service utilization
}

This article was published in the following Dove Press journal:

International Journal of COPD

\author{
Maryse Bélanger ${ }^{1,2}$ \\ Simon Couillard ${ }^{1,2}$ \\ Josiane Courteau' \\ Pierre Larivée ${ }^{1,2}$ \\ Thomas G Poder ${ }^{1,3,4}$ \\ Nathalie Carrier' \\ Kim Girard' \\ Felix-Antoine Vézina ${ }^{1,2}$ \\ Alain Vanasse ${ }^{1,4}$ \\ 'Research Center, Centre hospitalier \\ universitaire de Sherbrooke, \\ Sherbrooke, QC, Canada; \\ ${ }^{2}$ Respirology Service, Department \\ of Medicine, Faculty of Medicine \\ and Health Sciences, Université \\ de Sherbrooke, Sherbrooke, \\ QC, Canada; ${ }^{3}$ Health Technology \\ Assessment Unit, UETMIS, CIUSSS \\ de l'Estrie - CHUS, Sherbrooke, \\ QC, Canada; ${ }^{4}$ Department of Family \\ Medicine and Emergency Medicine, \\ Faculty of Medicine and Health \\ Sciences, Université de Sherbrooke, \\ Sherbrooke, QC, Canada
}

Correspondence: Alain Vanasse Department of Family Medicine and Emergency Medicine, 300 I, 12th Avenue North, Sherbrooke, QC JIH $5 \mathrm{~N} 4$, Canada

Tel + I 8198218000 ext 70540

Fax +l 8195645386

Email alain.vanasse@usherbrooke.ca
Purpose: Current evidence suggests that a higher blood eosinophil cell count at admission for acute exacerbation of COPD (AECOPD) is associated with a favorable response to systemic steroids. However, the impact of blood eosinophil counts at admission on post-hospitalization outcomes is still unclear. The main objective of this study is to investigate readmission outcomes associated with blood eosinophilia following severe COPD exacerbation in patients with infrequent COPD hospitalizations.

Patients and methods: This is an observational cohort study design. We retrospectively analyzed data of patients with a first hospitalization within 5 years for COPD exacerbation between April 2006 and March 2013. Patients were stratified into the eosinophilic group if the blood eosinophil count on admission was $\geq 200$ cells $/ \mu \mathrm{L}$ and $/$ or $\geq 2 \%$ of the total white blood cell (WBC) count. The primary outcome was 1-year COPD-related readmission. Secondary outcomes included 1-year all-cause mortality, 1-year all-cause readmission, length of stay, time to COPD-related readmission, and number of 1-year COPD-associated emergency department (ED) and ambulatory visits.

Results: A total of 479 patients were included. Of whom, 173 were stratified into the eosinophilic group. Higher blood eosinophil cell count was associated with an increased risk of 1-year COPD-related readmission (OR, 1.83 [95\% CI, 1.16-2.89]; $P<0.01$ ), a shorter time to first COPD-related readmission (HR, 1.64 [95\% CI, 1.14-2.36]; $P<0.01$ ), and an increased number of 1-year COPD-related ED visits (incidence rate ratio, 1.78 [95\% CI, 1.21-2.61]; $P<0.01$ ). All-cause mortality, all-cause readmission, length of stay, and number of ambulatory visits did not differ between groups.

Conclusion: Higher blood eosinophil cell count at admission for a COPD exacerbation is associated with increased COPD readmission rates in patients with infrequent COPD hospitalizations.

Keywords: COPD, exacerbations, hospitalization, mortality, cohort study

\section{Introduction}

Acute exacerbations of COPD (AECOPD) are associated with increased mortality, accelerated loss of lung function, and substantial health care costs. ${ }^{1}$ COPD 30-day readmission rates are as high as $20 \%$ in the United States. ${ }^{2}$ In Canada, COPD accounts for the highest rates of hospitalization and highest number of readmissions among all chronic illnesses. ${ }^{3}$ Thus, it is of primary importance to find a biomarker that could predict readmission outcomes and direct targeted treatment strategies.

Although classically neutrophilic, a subset of patients with COPD demonstrates an eosinophilic inflammatory profile. ${ }^{4}$ Sputum eosinophilia has long been associated with non-infectious exacerbations, ${ }^{5}$ as well as systemic and inhaled corticosteroid (ICS) responsiveness. ${ }^{6,7}$ However, measurement of sputum eosinophils is not available in 
most medical centers. Recently, Bafadhel et $\mathrm{al}^{5}$ demonstrated that blood eosinophil counts $\geq 2 \%$ of white blood cell (WBC) count can be used as a surrogate for sputum eosinophilia. Up to $40 \%$ of the patients hospitalized for COPD exacerbation exhibit blood eosinophil counts $\geq 2 \%$ at admission. ${ }^{8-10}$ Recent studies support that these patients behave like those with high sputum eosinophils, therefore representing a different COPD phenotype ${ }^{6}$ having distinct clinical outcomes and treatment response..$^{8,11-15}$

The impact of blood eosinophil counts at admission for COPD exacerbation on readmission rates is still unclear. While some retrospective and post-hoc analyses demonstrated an association between higher blood eosinophil counts and increased readmission rates, ${ }^{9,16,17}$ others did not ${ }^{14}$ and some even found fewer readmissions in patients with eosinophilic exacerbations. ${ }^{18}$ By analyzing these conflicting results, Couillard et $\mathrm{al}^{9}$ raised the possibility that the timing of corticosteroid administration could be a confounding factor. Eosinophil count falls by $>50 \%$ within 4 hours following systemic corticosteroid administration and returns to baseline within 24 hours. ${ }^{19}$ The timing of corticosteroid administration in relation to the WBC count could have potentially masked peripheral eosinophilia in certain patients in previous studies. ${ }^{9,19}$ This can lead to the inclusion of patients who would otherwise have higher eosinophil counts in the noneosinophilic patient group and lead to non-significant results. In a retrospective observational cohort study of 167 hospitalized patients, excluding those who recently received systemic corticosteroids, they demonstrated a more than threefold increase in 1-year COPD readmission in patients with higher blood eosinophil counts. ${ }^{9}$

Eosinophilic inflammation in COPD has been extensively investigated in samples of patients with well-established COPD. However, to our knowledge, whether this inflammatory profile is of any clinical significance in COPD patients with infrequent exacerbations has not yet been explored. Moreover, there is still debate about the best eosinophil cutoff level to use in this setting. Hence, the main objective of this study was to investigate the association between eosinophil counts and adverse clinical outcomes following first hospitalization for COPD exacerbation in patients with infrequent exacerbations. A secondary objective included assessing adverse clinical outcome rates with different blood eosinophil counts.

\section{Patients and methods}

\section{Study design and data sources}

This is a non-interventional observational cohort study using linked real-world clinical and medical administrative data.
The study cohort was extracted from the electronic medical records located in the hospital health centers of Sherbrooke, Quebec, Canada. It included all patients hospitalized for COPD between April 2006 and March 2013. This index hospitalization had to be the first in the last 5 years. This was ensured by linking data to the provincial administrative data from the Régie de l'assurance maladie du Québec (RAMQ) and the Ministère de la santé et des services sociaux (MSSS) to obtain all health care services used and outcomes from April 2001 to March 2014 and up to 1 year following the index hospitalization. Additional data collected by manual extraction from medical charts consisted of the following: smoking status; home oxygen use; baseline pulmonary function test (PFT) results before and up to 1 year following index hospitalization (PFT used, in order of priority: most recent $\mathrm{PFT}<5$ years prior to admission, $\mathrm{PFT}>1$ year after discharge, and PFT between 1998 and $>5$ years prior); baseline and discharge inhaler therapy; corticosteroid use within 48 hours before index admission, inpatient definitive treatment components, such as corticosteroids and/or antimicrobial agents; and date and time of the first corticosteroid dose. Using a unique encrypted identifier, patient files from different sources were linked to provide demographic characteristics, medical, and clinical information. This project was approved by the institutional ethics committee (Comité d'éthique de la recherche du Centre hospitalier universitaire de Sherbrooke \#2014-696, 13-181).

\section{Study population}

\section{Inclusion and exclusion criteria}

Patients included were hospitalized for COPD (main diagnosis ICD-10: J40-J44) at the hospital centers of Sherbrooke, Quebec, Canada, between April 2006 and March 2013. They were all 40-84 years old, treated with two or more respiratory drugs for their COPD during hospitalization, discharged alive, and without a previous hospitalization for asthma in the past 5 years. Respiratory drugs were as follows: short-acting beta agonist (SABA), long-acting beta agonist (LABA), longacting muscarinic antagonist (LAMA), ICS, and theophylline. As done previously, ${ }^{20,21}$ we only included patients treated with at least two respiratory drugs to increase the likelihood of a correct COPD diagnosis. In order to recruit patients with infrequent exacerbations, we excluded those who were hospitalized for COPD in the previous 5 years before the index hospitalization. Further exclusion criteria that were applied after manual extraction from medical charts are as follows: absence of a fixed obstructive pattern on PFT results $\left(\mathrm{FEV}_{1} / \mathrm{FVC}\right.$ ratio $\geq 70$ or absence of any valid PFT result), subjects mislabeled as COPD (never smokers, including the 
ones with an obstructive pattern on PFT, or no mention of COPD in medical records), COPD without acute exacerbation, and patients with pneumonia. Patients purely labeled as asthmatics were excluded, but we included patients with asthma-COPD overlap (ACO). Unfortunately, we could not accurately identify ACO patients due to the lack of definition of this entity in the years of our retrospective study. As done previously, ${ }^{9}$ we also excluded patients not "corticosteroidfree" at the time of blood sampling (defined as systemic corticosteroid use between 1 and 48 hours before venipuncture) to reduce the confounding factor that could be the eosinopenic effect of corticosteroids on group stratification.

\section{Outcomes}

The primary outcome was 1-year COPD-related readmission (yes/no). Secondary outcomes were as follows: 1-year all-cause mortality (yes/no), 1-year all-cause readmission (yes/no), index hospital length of stay, number of all-cause and COPD-related emergency department (ED) visits, number of all-cause and COPD-related ambulatory care visits, and time until COPD-related readmission. For each patient, we obtained information from the provincial administrative data (RAMQ/MSSS) regarding outcomes and health care service utilization for the first-year period (365 days) following discharge from the index hospitalization.

\section{Independent variable}

The main independent variable was binary (yes/no) and related to the blood eosinophil cell count $\geq 200$ cells $/ \mathrm{mL}$ and/or $\geq 2 \%$ of the total WBC count on the first inpatient complete blood count $(\mathrm{CBC})$ available during the index hospitalization (including ED care). This threshold has previously shown high sensitivity for predicting sputum eosinophilia and was thus considered to indicate an "eosinophilic COPD patient". Sensitivity analyses were conducted on the primary outcome to evaluate the use of other cutoffs in eosinophilia.

\section{Covariables}

Other variables that were considered in statistical models include the following: age, sex, smoking status (ex-smoker, current smoker), WBC count at admission, $\mathrm{FEV}_{1}, \mathrm{FEV}_{1} / \mathrm{FVC}$ ratio, GOLD spirometry-based severity classification stage (according to $\mathrm{FEV}_{1}$ ), home oxygen use, intensive care unit (ICU) stay (yes/no), intubation and mechanical ventilation (yes/no), baseline and discharge inhaler therapy, index hospital length of stay, intensity of used care index, Charlson comorbidity index (CCI), and specific comorbidities (cardiovascular disease [CVD], diabetes, asthma, and mental disorders). These variables were selected because they may possibly influence the main outcome. D'Hoore et al's ${ }^{22}$ version of the CCI was calculated using diagnoses reported during a hospitalization or during a physician's visit in the year prior and including the index hospitalization. The intensity of used care index measures the relative amount of resources used during a hospitalization. To handle missing values on medication use, we randomly imputed 0 or 1 in the same proportion as observed for the nonmissing observations.

\section{Statistical analyses}

The study variables were compared between eosinophilic and non-eosinophilic patients using the chi-squared test for categorical variables and the Student's $t$-test or the Wilcoxon rank test for continuous variables. To measure associations between eosinophilia and outcomes, we applied the following steps. Step 1: only covariates statistically associated (with $P<0.1)$ with the outcome in the univariate analysis were considered in the multivariate model. Step 2: a backward elimination process was performed to include only statistically significant (with $P<0.05$ ) covariates in the model. We performed the following models: logistic regression models for binary outcomes (all-cause mortality, all-cause readmission, and COPD-related readmission); negative binomial regression models for count outcomes (hospital length of stay, number of all-cause COPD-related ED visits, and number of all-cause and COPD-related ambulatory care visits); Cox regression models and Kaplan-Meier survival curves for time to first COPD-related readmission. For this outcome, we censured patients at the date of death if deceased or at the end of follow-up (365 days). We performed sensitivity analyses on the primary outcome with various definitions of eosinophilia. We performed these using the same adjusting covariates as the original model (the model with eosinophilia defined as $\geq 200$ cells $/ \mathrm{mL}$ or $\geq 2 \%$ of WBC). A $P$-value of $\leq 0.05$ was considered as a significant difference.

\section{Results}

A total of 1,440 patients aged 40-84 years were hospitalized with a main diagnosis of COPD at the Hospital centers of Sherbrooke between April 2006 and March 2013, treated with two or more respiratory drugs for their COPD during hospitalization, without a previous hospitalization for asthma in the past 5 years, and discharged alive. For 1,129 (78.4\%) of them, this was their first COPD hospitalization over a 5-year period. Among this cohort, we retained 479 (42.4\%) patients after applying other exclusion criteria (Figure 1). A total of 62 patients were part of our previous study, ${ }^{9}$ representing around one-third of the previous study size $(n=167)$ and $13 \%$ of the present cohort size $(n=479)$. 


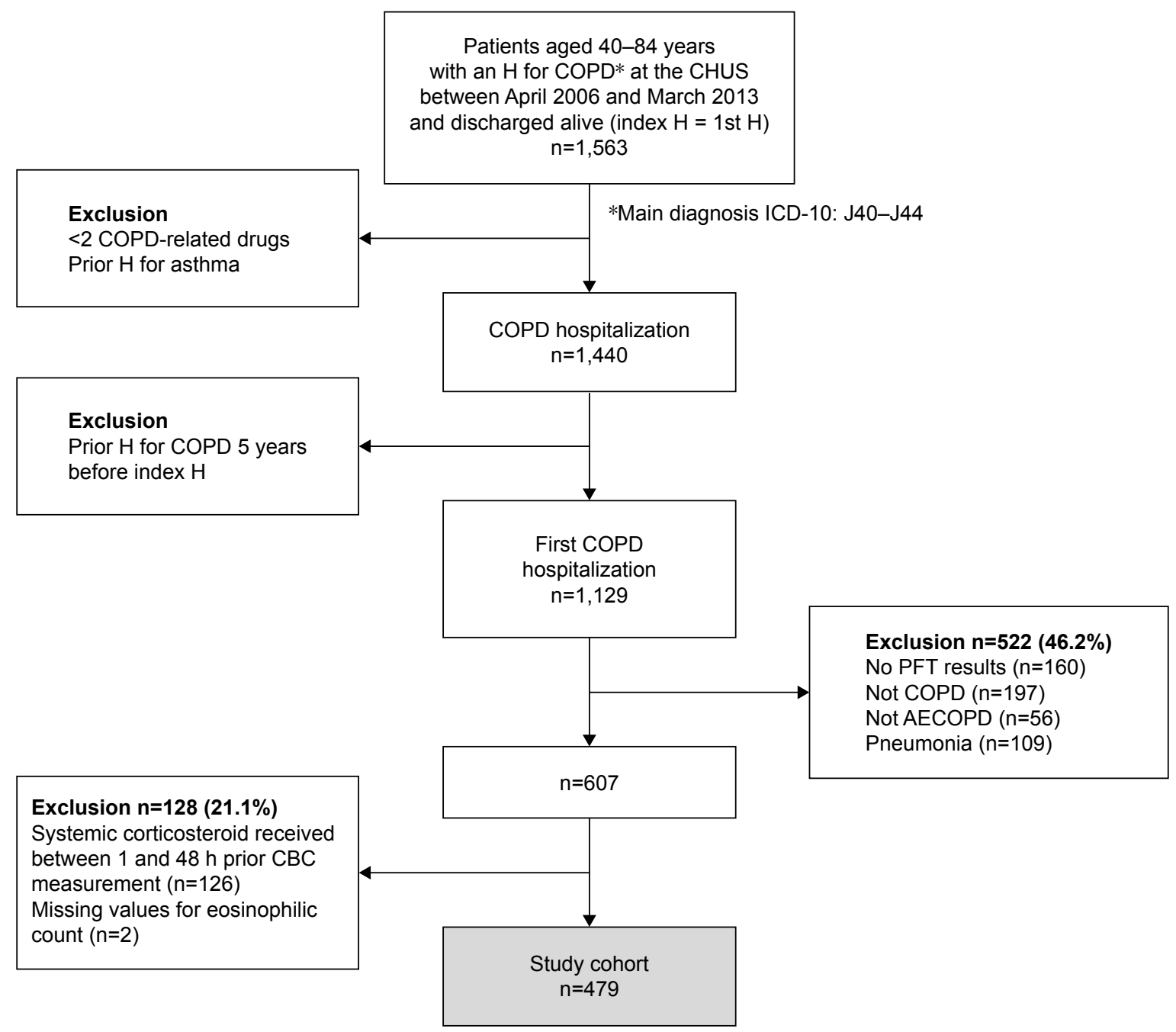

Figure I Flowchart of patient selection process.

Abbreviations: AECOPD, acute exacerbation of COPD; CBC, complete blood count; CHUS, Centre hospitalier universitaire de Sherbrooke; h, hours; H, hospitalization; PFT, pulmonary function test.

Over one-third of the patients $(\mathrm{n}=173)$ were considered eosinophilic ( $\geq 200 \mathrm{cells} / \mathrm{mL}$ and/or $\geq 2 \%$ of the total WBC count). Characteristics between eosinophilic and non-eosinophilic patients were generally similar (Table 1). Overall, 50 patients $(10.4 \%)$ died 1 year after being discharged alive from their first COPD hospitalization, more than half (53.9\%) of the patients were readmitted from any cause, and nearly $25 \%$ were readmitted for COPD.

The primary outcome (1-year COPD-related readmission) differed significantly between groups (adjusted OR [95\% CI], eosinophilic vs non-eosinophilic: 1.83 [1.16-2.89], $P=0.009$; Table 2). The Kaplan-Meier curves (Figure 2) clearly show this difference.

We also compared the primary outcome using different eosinophil cell count cutoffs (Table 1). Those sensitivity analyses revealed a proportional increase in size effect with increasing eosinophil cell count on 1-year COPD-related readmission.
Among secondary outcomes, and using the main definition of eosinophilia ( $\geq 200$ cells $/ \mathrm{mL}$ and/or $\geq 2 \%$ of the total WBC count), we found that the time to COPD-related readmission (adjusted HR [95\% CI]: 1.64 [1.14-2.36], $P=0.007$ ) and the number of COPD-related ED visits (adjusted $\exp (\beta)$ [95\% CI]: 1.78 [1.21-2.61], $P=0.003)$ were significantly different between groups. All-cause mortality, all-cause readmission, the length of hospital stay, the number of ED visits, the number of ambulatory visits, and the number of ambulatory COPD visits did not differ significantly between groups (Table 3). Our analyses performed on complete cases only resulted in the same conclusions (data not shown).

\section{Discussion}

The main finding of this study is that an increased blood eosinophil count at admission (defined as $\geq 200$ cells $/ \mu \mathrm{L}$ and/or $\geq 2 \%$ of the WBC count) is associated with adverse 
Table I Patients' characteristics by eosinophilic group ( $\geq 200$ cells $/ \mathrm{mL}$ or $\geq 2 \%$ )

\begin{tabular}{|c|c|c|c|c|}
\hline Variables & Total $(n=479)$ & $\begin{array}{l}\text { Eosinophilic } \\
\text { COPD }(n=\mid 73)\end{array}$ & $\begin{array}{l}\text { Non-eosinophilic } \\
\text { COPD }(n=306)\end{array}$ & $P$-value \\
\hline Male & $249(52.0)$ & $98(56.6)$ & I5I (49.4) & 0.124 \\
\hline Age, years & $68.9 \pm 9.4$ & $68.7 \pm 9.4$ & $69.1 \pm 9.4$ & 0.677 \\
\hline \multicolumn{5}{|l|}{ Comorbidities } \\
\hline CVD & $299(62.4)$ & $107(61.8)$ & $192(62.8)$ & 0.846 \\
\hline Diabetes & $105(21.9)$ & $42(24.3)$ & $63(20.6)$ & 0.348 \\
\hline Mental disorder & $244(50.9)$ & $91(52.6)$ & $153(50.0)$ & 0.584 \\
\hline Charlson comorbidity index & $2[0-3]$ & $2[0-3]$ & $2[0-3]$ & 0.792 \\
\hline Current smoker & $260(54.3)$ & $88(50.9)$ & $172(56.2)$ & 0.260 \\
\hline ICU stay & $38(7.9)$ & II (6.4) & $27(8.8)$ & 0.338 \\
\hline Intensity of care index & $0.89[0.69-0.94]$ & $0.88[0.68-1.00]$ & $0.89[0.69-0.94]$ & 0.539 \\
\hline Intubation & $69(14.4)$ & $17(9.8)$ & $52(17.0)$ & 0.032 \\
\hline FEV (post-broncho), \%predicted & $51.2 \pm 16.8$ & $52.0 \pm 17.4$ & $50.7 \pm 16.5$ & 0.397 \\
\hline $\mathrm{FEV}_{\mathrm{I}} / \mathrm{FVC}, \%$ & $47.0 \pm 12.1$ & $47.0 \pm 12.9$ & $47.0 \pm 11.6$ & 0.964 \\
\hline \multicolumn{5}{|l|}{ GOLD stage (by $\mathrm{FEV}_{\mathrm{l}}$ ) } \\
\hline $\mathrm{I}$ & $30(6.3)$ & $13(7.5)$ & $17(5.6)$ & 0.726 \\
\hline II & $216(45.1)$ & $80(46.2)$ & I36 (44.4) & \\
\hline III & $196(40.9)$ & $66(38.2)$ & I $30(42.5)$ & \\
\hline IV & $37(7.7)$ & $14(8.1)$ & $23(7.5)$ & \\
\hline Home oxygen use & $40(8.4)$ & $16(9.2)$ & $24(7.8)$ & 0.593 \\
\hline \multicolumn{5}{|l|}{ Baseline inhalator use $^{\mathrm{a}}$} \\
\hline ICS & $240(5 \mathrm{I} .4)$ & $87(51.5)$ & I53 (5I.3) & 0.977 \\
\hline LABA & $218(46.7)$ & $81(47.9)$ & $137(46.0)$ & 0.684 \\
\hline LAMA & $222(47.5)$ & $74(43.8)$ & I 48 (49.7) & 0.222 \\
\hline SAMA & $104(22.3)$ & $36(21.3)$ & $68(22.8)$ & 0.705 \\
\hline None or SABA prn only & $97(20.8)$ & $36(21.3)$ & $61(20.5)$ & 0.831 \\
\hline \multicolumn{5}{|l|}{ Discharge prescription ${ }^{b}$} \\
\hline ICS & $312(70.9)$ & II 3 (7I.5) & $199(70.6)$ & 0.833 \\
\hline LABA & $299(68.0)$ & II 2 (70.9) & $187(66.3)$ & 0.324 \\
\hline LAMA & $330(75.2)$ & $119(75.3)$ & $211(75.1)$ & 0.958 \\
\hline SAMA & $64(14.5)$ & $23(14.5)$ & $4 \mathrm{I}(14.5)$ & 0.983 \\
\hline None or SABA prn only & $12(2.7)$ & $5(3.1)$ & $7(2.5)$ & 0.681 \\
\hline Corticosteroid during index $\mathrm{H}$ & $442(92.3)$ & $163(94.2)$ & $279(91.2)$ & 0.231 \\
\hline Corticosteroid by injection & $118(24.6)$ & $43(24.9)$ & $75(24.5)$ & 0.933 \\
\hline Antibiotic during index $\mathbf{H}$ & $367(76.6)$ & $118(68.2)$ & $249(81.4)$ & $0.00 \mathrm{I}$ \\
\hline WBC count at admission, $\left(\times 10^{9} / \mathrm{L}\right)$ & $10.2 \pm 4.0$ & $9.9 \pm 4.2$ & $10.3 \pm 3.9$ & 0.347 \\
\hline Eosinophil count, cells $\times 10^{9} / \mathrm{L}$ & $0.1[0.0-0.2]$ & $0.3[0.2-0.4]$ & $0.0[0.0-0.1]$ & $<0.001$ \\
\hline Eosinophil count, \% of WBC & $\mathrm{I} .0[0.3-2.2]$ & $3.1[2.1-5.5]$ & $0.5[0.1-1.0]$ & $<0.001$ \\
\hline
\end{tabular}

Notes: $\mathrm{n}(\%)$ or mean $\pm S D$ or median [interquartile range]. Chi-squared test for categorical variables and the Student's $t$-test or the Wilcoxon rank test for continuous data. Bold values indicate a statistical significant difference between groups. aMissing values: 12. 'Missing values: between 38 and 40 .

Abbreviations: CBC, complete blood count; CVD, cardiovascular disease; ICS, inhaled corticosteroid; H, hospitalization; ICU, intensive care unit; LABA, long-acting beta agonist; LAMA, long-acting muscarinic antagonist; prn, as needed; SAMA, short-acting muscarinic antagonist; WBC, white blood cells.

readmission outcomes even in patients with infrequent COPD exacerbations. We observed an increase in 1-year COPD-related readmissions (OR, 1.83 [95\% CI, 1.16-2.89]; $P<0.01$ ), an increase in 1-year COPD-related ED visits (incidence rate ratio, 1.78 [95\% CI, 1.21-2.61]; $P<0.01$ ), and a shorter time to first COPD-related readmission (HR, 1.64
[95\% CI, 1.14-2.36]; $P<0.01)$. This influence of eosinophil cell counts on readmissions is consistent throughout the sensitivity analyses conducted on our data.

In this study, the increased risk of COPD-related 1-year readmission conferred by higher blood eosinophil counts is lower than our group previously observed in a smaller sample 
Table 2 Association between eosinophilia and I-year COPD-related readmission according to eosinophilia definition

\begin{tabular}{|c|c|c|c|c|c|}
\hline $\begin{array}{l}\text { Definition of } \\
\text { eosinophilia }\end{array}$ & Total $(n=479)$ & $\begin{array}{l}\text { COPD-related } \\
\text { readmission } \\
(n=119)\end{array}$ & $\begin{array}{l}\text { No COPD-related } \\
\text { readmission } \\
(n=360)\end{array}$ & $\begin{array}{l}\text { Unadjusted } \\
\text { OR }\end{array}$ & Adjusted OR \\
\hline \multicolumn{6}{|l|}{ Main definition } \\
\hline$<200$ and $<2 \%$ & 306 (63.9) & $65(54.6)$ & $24 I$ (66.9) & 1.0 & 1.0 \\
\hline$\geq 200$ cells $/ \mu \mathrm{L}$ or $\geq 2 \%$ & $173(36.1)$ & $54(45.4)$ & $119(33.1)$ & $1.69(1.10-2.60)^{\mathrm{a}}$ & $1.83(1.16-2.89)^{\mathrm{b}}$ \\
\hline \multicolumn{6}{|l|}{ Other definitions } \\
\hline$<300$ and $<3 \%$ & $376(78.5)$ & $83(69.8)$ & $293(8 I .4)$ & 1.0 & 1.0 \\
\hline$\geq 300$ cells $/ \mu \mathrm{L}$ or $\geq 3 \%$ & $103(2 \mid .5)$ & $36(30.2)$ & $67(18.6)$ & $1.94(1.20-3.14)^{b}$ & $1.99(1.19-3.30)^{\mathrm{b}}$ \\
\hline$<400$ and $<4 \%$ & $408(85.2)$ & $92(77.3)$ & $316(87.8)$ & 1.0 & 1.0 \\
\hline$\geq 400$ cells $/ \mu \mathrm{L}$ or $\geq 4 \%$ & $7 \mid(\mid 4.8)$ & $27(22.7)$ & $44(12.2)$ & $1.94(1.14-3.32)^{\mathrm{a}}$ & $2.10(1.20-3.68)^{\mathrm{b}}$ \\
\hline$<200$ cells $/ \mu \mathrm{L}$ & $319(66.6)$ & $66(55.5)$ & $253(70.3)$ & 1.0 & 1.0 \\
\hline 200-300 cells/ $\mu \mathrm{L}$ & $68(14.2)$ & $19(16.0)$ & $49(13.6)$ & I.55 (0.85-2.84) & $1.57(0.83-2.97)$ \\
\hline 300-400 cells/ $\mu \mathrm{L}$ & $30(6.3)$ & $8(6.7)$ & $22(6.1)$ & $1.56(0.65-3.75)$ & $1.36(0.53-3.50)$ \\
\hline$\geq 400$ cells $/ \mu \mathrm{L}$ & $62(12.9)$ & $26(21.8)$ & $36(10.0)$ & $2.61(1.47-4.65)^{\mathrm{b}}$ & $2.60(1.43-4.76)^{\mathrm{b}}$ \\
\hline$<2 \%$ & $336(70.2)$ & $74(62.2)$ & $262(72.8)$ & 1.0 & 1.0 \\
\hline $2.0 \%-3.0 \%$ & $54(11.3)$ & $12(10.1)$ & $42(11.7)$ & $1.02(0.5 \mathrm{I}-2.05)$ & $1.29(0.6 \mathrm{I}-2.72)$ \\
\hline $3.0 \%-4.0 \%$ & $30(6.3)$ & $10(8.4)$ & $20(5.6)$ & $2.02(0.88-4.64)$ & $2.66(1.09-6.49)^{\mathrm{a}}$ \\
\hline$\geq 4.0 \%$ & $59(12.3)$ & $23(19.3)$ & $36(10.0)$ & $2.12(1.18-3.82)^{\mathrm{a}}$ & $2.4 \mathrm{I}(\mathrm{I} .29-4.49)^{\mathrm{b}}$ \\
\hline$<400$ and $<3 \%$ & $387(80.8)$ & $86(72.3)$ & $30 I(83.6)$ & 1.0 & 1.0 \\
\hline$\geq 400$ cells $/ \mu \mathrm{L}$ or $\geq 3 \%$ & $92(19.2)$ & $33(27.7)$ & $59(16.4)$ & $1.94(1.18-3.20)^{\mathrm{b}}$ & $2.20(1.30-3.72)^{\mathrm{b}}$ \\
\hline $\begin{array}{l}\text { Absolute eosinophil cell } \\
\text { count (continuous) }\end{array}$ & Mean I7I (SD 257) & Mean 242 (SD 34I) & Mean I47 (SD 2 I8) & $1.13^{\mathrm{c}}(1.05-1.23)^{\mathrm{b}}$ & $1.14^{\mathrm{c}}(1.06-1.24)^{\mathrm{b}}$ \\
\hline $\begin{array}{l}\text { \% eosinophil cell counts } \\
\text { (continuous) }\end{array}$ & Mean I.9 (SD 2.5) & Mean 2.28 (SD 2.7) & Mean I.7 (SD 2.4) & $1.07^{\mathrm{d}}(1.00-1.17)^{\mathrm{a}}$ & $1.08^{\mathrm{d}}(1.00-1.17)^{\mathrm{a}}$ \\
\hline
\end{tabular}

Notes: OR (logistic regression) $(95 \% \mathrm{Cl})$; ${ }^{\mathrm{a}} \mathrm{P}<0.05$; ${ }^{\mathrm{b}} \mathrm{P}<0.0 \mathrm{I}$. ${ }^{\mathrm{c} P e r}$ increase of 100 cell counts. ${ }^{\mathrm{d} P e r}$ increase of $\mathrm{I} \%$.
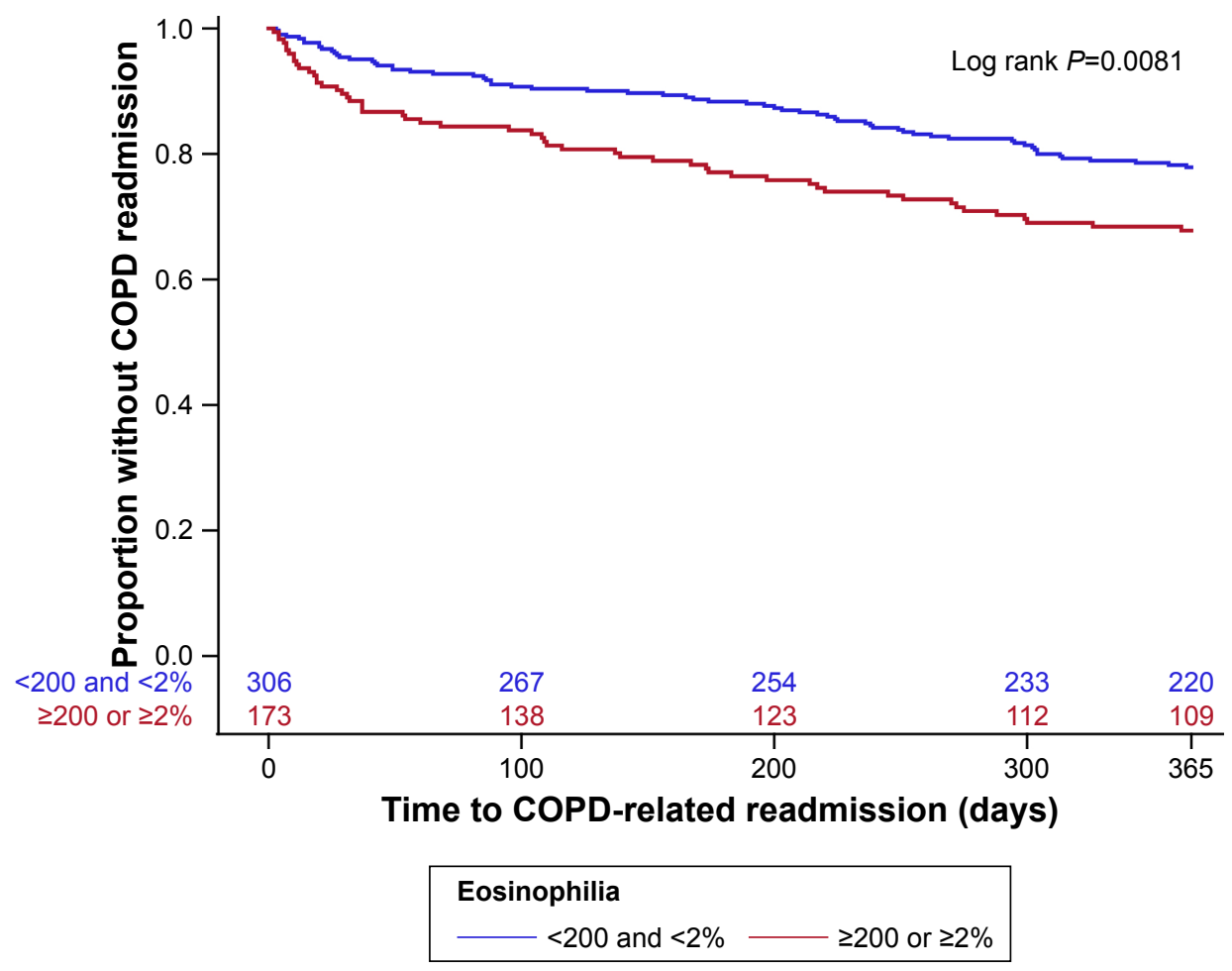

Figure 2 Kaplan-Meier curves for time until first COPD-related readmission: eosinophilic (red line) vs non-eosinophilic patients (blue line). 
Table 3 Association between eosinophilia ( $\geq 200$ cells $/ \mathrm{mL}$ or $\geq 2 \%$ ) and secondary outcomes

\begin{tabular}{|l|l|l|l|l|}
\hline Secondary outcome & $\begin{array}{l}\text { Eosinophilic COPD } \\
(\mathbf{n}=\mathbf{I 7 3})\end{array}$ & $\begin{array}{l}\text { Non-eosinophilic } \\
\text { COPD }(\mathbf{n}=\mathbf{3 0 6})\end{array}$ & Unadjusted ES & Adjusted ES \\
\hline Time to COPD-related readmission, days & $27 \mathrm{I} .8(\mathrm{I} 36.6)$ & $305 . \mathrm{I}(\mathrm{II} 2.6)$ & $\mathrm{I} .62(\mathrm{I} .13-2.32)^{\mathrm{a}}$ & $\mathrm{I} .64(\mathrm{I} . \mathrm{I}-2.36)^{\mathrm{a}}$ \\
\hline I-year all-cause death & $\mathrm{n}=\mathrm{I} 6(9.2 \%)$ & $\mathrm{n}=34(\mathrm{II} .1 \%)$ & $0.82(0.44-\mathrm{I} .52)$ & $0.82(0.42-\mathrm{I} .6 \mathrm{I})$ \\
\hline I-year all-cause readmission & $\mathrm{n}=98(56.6 \%)$ & $\mathrm{n}=\mathrm{I} 60(62.0 \%)$ & $\mathrm{I} .20(0.82-\mathrm{I} .75)$ & $\mathrm{I} .28(0.86-\mathrm{I} .90)$ \\
\hline Length of stay, days & $4[3-7]$ & $4[3-7]$ & $\mathrm{I} .00(0.86-\mathrm{I} .15)$ & $\mathrm{I} .08(0.95-\mathrm{I} .23)$ \\
\hline Number of I-year all-cause ED visits & $\mathrm{I}[0-3]$ & $\mathrm{I}[0-3]$ & $\mathrm{I} .30(0.99-\mathrm{I} .70)$ & $\mathrm{I} .26(0.97-\mathrm{I} .64)$ \\
\hline Number of I-year COPD-related ED visits & $\geq \mathrm{I}: \mathrm{n}=60(34.7 \%)$ & $\geq \mathrm{I}: \mathrm{n}=75(24.5 \%)$ & $\mathrm{I} .68(\mathrm{I} .15-2.48)^{\mathrm{a}}$ & $\mathrm{I} .78(\mathrm{I} .2 \mathrm{I}-2.6 \mathrm{I})^{\mathrm{a}}$ \\
\hline Number of I-year all-cause ambulatory visits & $5[2-8]$ & $5[2-9]$ & $0.90(0.75-\mathrm{I} .07)$ & $0.84(0.7 \mathrm{I}-\mathrm{I} .00)$ \\
\hline Number of I-year ambulatory COPD visits & $\mathrm{I}[0-2]$ & $0.5[0-2]$ & $\mathrm{I} .20(0.9 \mathrm{I}-\mathrm{I} .58)$ & $\mathrm{I} .08(0.83-\mathrm{I} .40)$ \\
\hline
\end{tabular}

Notes: Mean (SD) or median [interquartile range]. (HR: HR in Cox regression; OR: OR in logistic regression; exp ( $\beta$ ) in negative binomial regressions) $(95 \% \mathrm{Cl})$. ${ }^{\mathrm{a}} \mathrm{P}<0.0 \mathrm{O}$. Abbreviations: ED, emergency department; ES, effect size.

of COPD patients. ${ }^{9}$ We must consider that the size effect may have been overestimated in our previous sample of lesser size. Also, in selecting infrequent COPD exacerbators, we may have selected COPD patients less prone to readmissions. ICSs are well known to lower the exacerbation rates; ${ }^{1}$ especially in COPD patients with higher blood eosinophil counts. ${ }^{11-13}$ In our sample, the proportion of patients using ICS after discharge is the same between the two groups. Also, baseline and discharge use of ICS has been used in our covariate analyses without any change in the effect of blood eosinophil count on readmission outcome. Thus, it is unlikely that the ICS effect on exacerbation rates would have distorted the results. Albeit of less magnitude than what has been previously observed in other studies, ${ }^{9}$ our current study looking at less frequent COPD exacerbators supports the observation that eosinophilic inflammation confers an increased risk of COPD-related readmission. Thus, blood eosinophil counts could be used as an early biomarker in COPD to predict readmissions.

Previous studies have demonstrated an association between higher eosinophil counts with better in-hospital outcomes. ${ }^{14,17,18,23}$ In a post hoc analysis of a prospective study, Bafadhel et al ${ }^{14}$ showed a shorter length of stay for patients with eosinophilic exacerbations in comparison to non-eosinophilic exacerbations. Other studies demonstrated the same association. ${ }^{17,18,23}$ In this study, we did not find this association. However, patients were only included if discharged alive. This could have led to underestimation of length of stay for either the eosinophilic or the non-eosinophilic group and made these data invalid for interpretation. One favorable in-hospital outcome that we found was that invasive mechanical ventilation rates were significantly lower $(9.8 \%$ vs $17 \% P<0.05)$ for patients with higher blood eosinophil counts. We did not have the data on non-invasive mechanical ventilation utilization. Although this must be interpreted with care, this is concordant with the higher mortality rates, ICU admissions, and mechanical ventilation in patients with lower eosinophil counts $(<50$ cells $/ \mu \mathrm{L})$ found in previous studies. ${ }^{17,24-26}$ The rapid response of eosinophilic exacerbations to corticosteroid treatment ${ }^{8,27}$ and the relatively poor prognosis associated with eosinopenia are two of many possible explanations for those better acute outcomes found in eosinophilic exacerbations. Without surprise and in line with previous report, ${ }^{5}$ eosinophilic patients were less likely to be treated with antibiotics during the index hospitalization, indicating that physicians identified non-purulent exacerbation in these patients. Noteworthy, better intra-hospitalization outcomes do not mirror post-hospitalization outcomes in COPD patients with higher blood eosinophil counts. Prins et al, ${ }^{17}$ in a post hoc analysis of a prospective study, found that blood eosinophilia $\geq 2 \%$ of WBC at admission for COPD exacerbation was not only associated with higher short-term treatment success but also predicted an increased risk of relapse. Thus, our finding that eosinophilic exacerbations are associated with higher rates of COPD-related readmissions does not contradict better in-hospital outcomes found in this group in previous studies. ${ }^{14,17,18,23}$

We used a blood eosinophil cutoff point of $\geq 200$ cells $/ \mu \mathrm{L}$ or $\geq 2 \%$ of WBC because it has been reported to have the best sensitivity and specificity for sputum eosinophil counts $\left(\geq 3 \%\right.$ ) during acute exacerbations and stable COPD. ${ }^{5,10}$ Most of the retrospective, observational, and post hoc analyses previously done used these cutoff values. ${ }^{910,14,16,18,23,27}$ However, the choice of a threshold value for a biomarker must be relevant for clinical outcomes, and there is still debate about the best eosinophil cutoff level and whether to use absolute or relative counts. ${ }^{4}$ In this study, we reported the results with different eosinophil count definitions. The KaplanMeier curves of time to first COPD-related readmission with different eosinophilia definitions (Figure 3) show that 
A

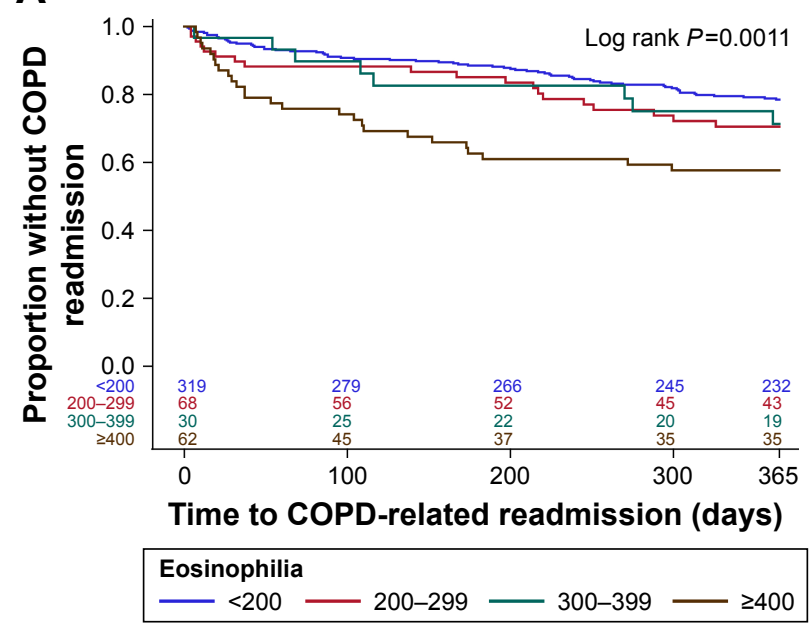

B

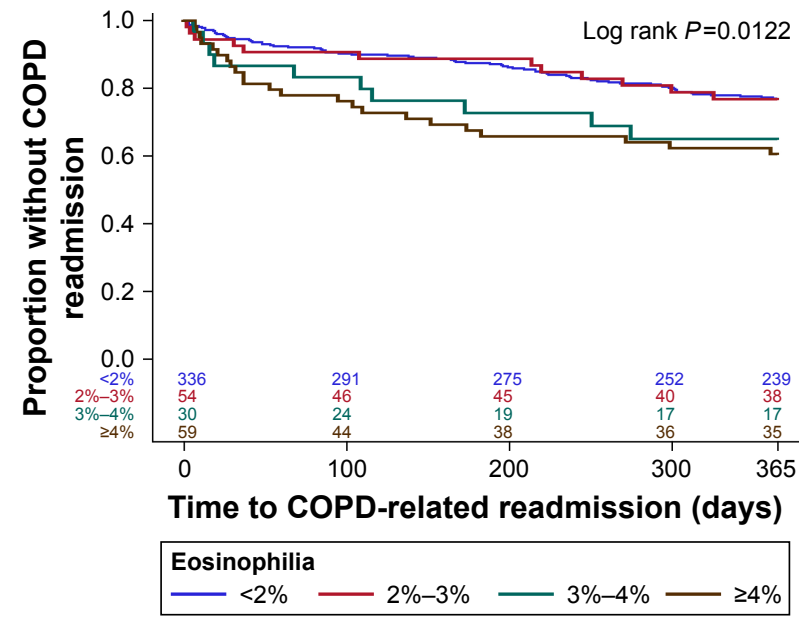

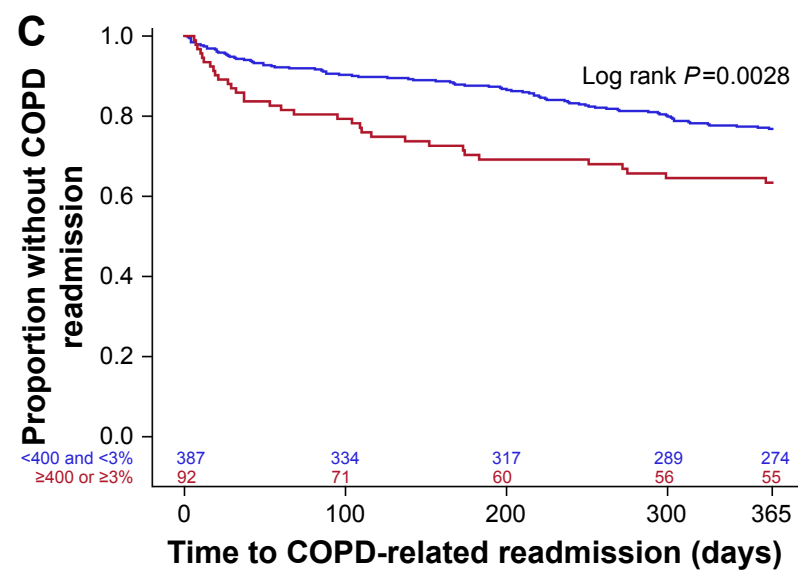

Eosinophilia

$<400$ and $<3 \%-\geq 400$ or $\geq 3 \%$

Figure 3 (A) Kaplan-Meier curves for time before first COPD-related readmission in patients with a corticosteroid-free CBC, with eosinophil counts $<200$ cells/ $\mu \mathrm{L}$ ( $\mathrm{n}=319$, blue line) vs 200-299 cells $/ \mu \mathrm{L}$ ( $\mathrm{n}=68$, red line) vs 300-399 cells $/ \mu \mathrm{L}$ ( $\mathrm{n}=30$, green line) vs $\geq 400$ cells $/ \mu \mathrm{L}$ ( $\mathrm{n}=62$, brown line); follow-up 365 days post-discharge, data censored for death; $P=0.00$ II. (B) Kaplan-Meier curves for time before first COPD-related readmission in patients with a corticosteroid-free CBC, with eosinophil counts $<2 \%$ of WBC count ( $n=336$, blue line) vs $2 \%-3 \%$ of WBC counts ( $n=54$, red line) vs $3 \%-4 \%$ of WBC counts ( $n=30$, green line) vs $\geq 4 \%$ of WBC counts ( $n=59$, brown line); follow-up 365 days post-discharge, data censored for death; $P=0.0122$. (C) Kaplan-Meier curves for time before first COPD-related readmission in patients with a corticosteroid-free CBC, with eosinophil counts $\geq 400$ cells/ $\mu \mathrm{L}$ and/or $\geq 3 \%$ of $W B C$ count ( $n=92$, red line) vs eosinophil counts $<400$ cells $/ \mu \mathrm{L}$ and $<3 \%$ of $W B C$ count ( $n=387$, blue line); follow-up 365 days post-discharge, data censored for death; $P=0.0028$.

Abbreviation: $\mathrm{CBC}$, complete blood count.

the increase in 1-year COPD-related readmission is mostly driven by eosinophil counts $\geq 400$ cells $/ \mu \mathrm{L}$ and/or $\geq 3 \%$ of WBC. Patients with eosinophil cell counts between $200-400$ cells $/ \mu \mathrm{L}$ and $2 \%-3 \%$ did not have a statistically significant increase in COPD-related readmission compared to those with eosinophil counts $<200$ cells $/ \mu \mathrm{L}$ or $<2 \%$ of WBC (Table 2).

These results are consistent with previous studies showing significant change in clinical outcomes in COPD patients using blood eosinophil counts $\geq 300-400$ cells/ $\mu \mathrm{L}$. . $^{10,16,28,29}$ However, more studies are needed to define a clear definition of eosinophilic COPD.
This study has some limitations. First, this is a singlecenter retrospective study and may thus be affected by the usual biases related to such studies. Large prospective studies are needed to confirm the signals provided by our real-world observational data. Second, patients had to be discharged alive to be included in this study. This could have influenced intra-hospitalized characteristics such as length of stay, rate of ICU utilization, and mechanical ventilation. Thus, no conclusions can be drawn from these data for outcomes during the hospitalization index. One major strength of this study is the consideration of the timing effect of systemic corticosteroid administration eosinophil counts. This possible bias 
of other studies has already been discussed extensively in a previous study. ${ }^{9}$ However, we must recognize that excluding such patients results in partially excluding patients experiencing outpatient treatment failure within the last 48 hours. Finally, other major strengths of this study are the evaluation of several different eosinophilia definitions and confirmation of COPD diagnosis with spirometry and smoking history. To our knowledge, it is the first sample assembled exclusively to study the association between blood eosinophil counts in a first COPD hospitalization and readmission outcomes.

The findings of this study have several clinical and research implications. First, even in the case of a first severe COPD exacerbation within the last 5 years, we observed great morbidity: in our sample, such patients had 54\% allcase readmission, 25\% COPD-related readmission, and $10 \%$ mortality rate in the following year. This emphasizes that a hospitalization for an AECOPD exacerbation should never simply be considered as "bad luck". Rather, this should prompt intensive treatment of comorbidities, optimization of pharmaceutical and non-pharmaceutical respiratory therapy, and provision of adequate follow-up. Second, we found that higher blood eosinophil counts in COPD exacerbation - as found in $36 \%$ of our sample - confer better in-hospital outcomes, although this conversely increases COPD-related readmissions. Whether we could learn more of this finding to better protect non-eosinophilic patients as inpatients and eosinophilic patients as outpatients remains to be seen. Finally, although initial phase III trials for anti-IL-5 treatments have proven somewhat contradictory, ${ }^{28,30,31}$ we believe that the abundant literature regarding worst exacerbation rates in COPD patients with higher blood eosinophil cell counts warrants the pursuit of targeted therapy at this level.

\section{Conclusion}

Among patients with infrequent hospitalizations for COPD, we found that higher blood eosinophil cell count at admission for a severe COPD exacerbation is associated with an increased 1-year COPD readmission rate and a shorter time to first COPD-related readmission. These results emphasize the role of blood eosinophil cell counts in COPD as a biomarker to predict hospital readmissions throughout the course of the disease.

\section{Acknowledgments}

This study was conducted with funding support from AstraZeneca Canada Inc. The sponsor had no role in the design of the study, the collection and analysis of the data, the statistical analyses, or the preparation of the manuscript.

\section{Disclosure}

AV and TGP report grants from AstraZeneca Canada Inc. during the conduct of the study. PL reports grants and personal fees from AstraZeneca, Boehringer Ingelheim, and Novartis, grants from Sanofi, and personal fees from Merck, outside the submitted work. The authors report no other conflicts of interest in this work.

\section{References}

1. Global Initiative for Chronic Obstructive Lung Disease. GOLD 2017 Global Strategy for the Diagnosis Management and Prevention of COPD. Available from: https://goldcopd.org/gold-2017-global-strategy-diagnosismanagement-prevention-copd/. Accessed September 6, 2018.

2. Dorsey K, Grady J, Desair N; Centers Medicare Medicaid Services; 2015. 2015 Condition-Specific Measures Updates and Specifications Report Hospital-Level 30-Day Risk-Standardized Readmission Measures. Available from: https://www.qualitynet.org/dcs/BlobSer ver?blobkey $=$ id\&blobnocache $=$ true $\&$ blobwhere $=1228890435217 \&$ blobheader $=$ multipart $\% 2$ Foctetstream\&blobheadername $1=$ Conten t-Disposition\&blobheadervalue $1=$ attachment $\% 3$ Bfilename $\% 3 \mathrm{DRd}$ mn_AMIHFPNCOPDSTK_Msr_UpdtRpt.pdf\&blobcol=urldata\&blo btable=MungoBlobs. Accessed September 7, 2018.

3. Canadian Institute for Health Information. Ottawa, ON: CIHI, 2012. All-Cause Readmission to Acute Care and Return to the Emergency Department. Available from: https://secure.cihi.ca/free_products/ Readmission_to_acutecare_en.pdf. Accessed September 7, 2018.

4. Bafadhel M, Pavord ID, Russell REK. Eosinophils in COPD: just another biomarker? Lancet Respir Med. 2017;5(9):747-759.

5. Bafadhel M, Mckenna S, Terry S, et al. Acute exacerbations of chronic obstructive pulmonary disease: identification of biologic clusters and their biomarkers. Am J Respir Crit Care Med. 2011;184(6): 662-671.

6. George L, Brightling CE. Eosinophilic airway inflammation: role in asthma and chronic obstructive pulmonary disease. Ther Adv Chronic Dis. 2016;7(1):34-51.

7. Siva R, Green RH, Brightling CE, et al. Eosinophilic airway inflammation and exacerbations of COPD: a randomised controlled trial. Eur Respir J. 2007;29(5):906-913

8. Bafadhel M, Davies L, Calverley PM, Aaron SD, Brightling CE, Pavord ID. Blood eosinophil guided prednisolone therapy for exacerbations of COPD: a further analysis. Eur Respir J. 2014;44(3): 789-791.

9. Couillard S, Larivée P, Courteau J, Vanasse A. Eosinophils in COPD Exacerbations Are Associated With Increased Readmissions. Chest. 2017; 151(2):366-373.

10. Hasegawa K, Camargo CA. Prevalence of blood eosinophilia in hospitalized patients with acute exacerbation of COPD. Respirology. 2016;21(4): 761-764.

11. Pascoe S, Locantore N, Dransfield MT, Barnes NC, Pavord ID Blood eosinophil counts, exacerbations, and response to the addition of inhaled fluticasone furoate to vilanterol in patients with chronic obstructive pulmonary disease: a secondary analysis of data from two parallel randomised controlled trials. Lancet Respir Med. 2015;3(6): 435-442.

12. Siddiqui SH, Guasconi A, Vestbo J, et al. Blood Eosinophils: A Biomarker of Response to Extrafine Beclomethasone/Formoterol in Chronic Obstructive Pulmonary Disease. Am J Respir Crit Care Med. 2015;192(4):523-525.

13. Pavord ID, Lettis S, Locantore N, et al. Blood eosinophils and inhaled corticosteroid/long-acting $\beta$-2 agonist efficacy in COPD. Thorax. 2016; 71(2):118-125.

14. Bafadhel M, Greening NJ, Harvey-Dunstan TC, et al. Blood Eosinophils and Outcomes in Severe Hospitalized Exacerbations of COPD. Chest. 2016;150(2):320-328 
15. Bafadhel M, Peterson S, de Blas MA, et al. Predictors of exacerbation risk and response to budesonide in patients with chronic obstructive pulmonary disease: a post-hoc analysis of three randomised trials. Lancet Respir Med. 2018;6(2):117-126.

16. Vedel-Krogh S, Nielsen S, Lange P, Vestbo JNB. Blood Eosinophils and Exacerbations in Chronic Obstructive. Am J Respir Crit Care Med. 2016;193(9):965-974.

17. Prins HJ, Duijkers R, Lutter R, et al. Blood eosinophilia as a marker of early and late treatment failure in severe acute exacerbations of COPD. Respir Med. 2017;131:118-124.

18. Duman D, Aksoy E, Coban Agca M, Agca MC, et al. The utility of inflammatory markers to predict readmissions and mortality in COPD cases with or without eosinophilia. Int J Chron Obstruct Pulmon Dis. 2015;10(1):2469-2478.

19. Thorn GW, Renold AE, Wilson DL, et al. Clinical studies on the activity of orally administered cortisone. N Engl J Med. 1951;245(15): 549-555.

20. Suissa S, dell'aniello S, Ernst P. Long-term natural history of chronic obstructive pulmonary disease: severe exacerbations and mortality. Thorax. 2012;67(11):957-963.

21. Ho TW, Tsai YJ, Ruan SY, et al. In-hospital and one-year mortality and their predictors in patients hospitalized for first-ever chronic obstructive pulmonary disease exacerbations: a nationwide population-based study. PLoS One. 2014;9(12):e114866.

22. D'Hoore W, Bouckaert A, Tilquin C, D'Hoore W, Bouchaert A, Tilquin C. Practical considerations on the use of the Charlson comorbidity index with administrative data bases. J Clin Epidemiol. 1996;49(12): 1429-1433.

23. Serafino-Agrusa L, Scichilone N, Spatafora M, Battaglia S. Blood eosinophils and treatment response in hospitalized exacerbations of chronic obstructive pulmonary disease: A case-control study. Pulm Pharmacol Ther. 2016;37(37):89-94.

24. Saltürk C, Karakurt Z, Adiguzel N, et al. Does eosinophilic COPD exacerbation have a better patient outcome than non-eosinophilic in the intensive care unit? Int J Chron Obstruct Pulmon Dis. 2015;10(1): 1837-1846.
25. Rahimi-Rad MH, Asgari B, Hosseinzadeh N, Eishi A. Eosinopenia as a Marker of Outcome in Acute Exacerbations of Chronic Obstructive Pulmonary Disease. Maedica. 2015;10(1):10-13.

26. Holland M, Alkhalil M, Chandromouli S, Janjua A, Babores M. Eosinopenia as a marker of mortality and length of stay in patients admitted with exacerbations of chronic obstructive pulmonary disease. Respirology. 2010;15(1):165-167.

27. Bafadhel M, Mckenna S, Terry S, et al. Blood eosinophils to direct corticosteroid treatment of exacerbations of chronic obstructive pulmonary disease: a randomized placebo-controlled trial. Am J Respir Crit Care Med. 2012;186(1):48-55.

28. Pavord ID, Chanez P, Criner GJ, et al. Mepolizumab for Eosinophilic Chronic Obstructive Pulmonary Disease. N Engl J Med. 2017;377: 1613-1629.

29. Hastie AT, Martinez FJ, Curtis JL, et al. Association of sputum and blood eosinophil concentrations with clinical measures of COPD severity: an analysis of the SPIROMICS cohort. Lancet Respir Med. 2017;5(12): 956-967.

30. Brightling CE, Bleecker ER, Panettieri RA, et al. Benralizumab for chronic obstructive pulmonary disease and sputum eosinophilia: a randomised, double-blind, placebo-controlled, phase 2a study. Lancet Respir Med. 2014;2(11):891-901.

31. AstraZeneca; 2018. Update on TERRANOVA Phase III trial for Fasenra in chronic obstructive pulmonary disease. Available from: https:// www.astrazeneca.com/media-centre/press-releases/2018/update-onterranova-phase-iii-trial-for-fasenra-in-chronic-obstructive-pulmonarydisease-30052018.html. Accessed July 9, 2018.
International Journal of COPD

\section{Publish your work in this journal}

The International Journal of COPD is an international, peer-reviewed journal of therapeutics and pharmacology focusing on concise rapid reporting of clinical studies and reviews in COPD. Special focus is given to the pathophysiological processes underlying the disease, intervention programs, patient focused education, and self management protocols.

\section{Dovepress}

This journal is indexed on PubMed Central, MedLine and CAS. The manuscript management system is completely online and includes a very quick and fair peer-review system, which is all easy to use. Visit http://www.dovepress.com/testimonials.php to read real quotes from published authors. 